\title{
PM chemical composition and oxidative potential of the soluble fraction of particles at two sites in the urban area of Milan, Northern Italy.
}

\author{
Maria Grazia Perrone*1, Jun Zhou ${ }^{2}$, Mery Malandrino ${ }^{3}$, Giorgia Sangiorgi ${ }^{1}$, Cristiana Rizzi ${ }^{1}$, Luca \\ Ferrero $^{1}$, Josef Dommen ${ }^{2}$, Ezio Bolzacchini ${ }^{1}$ \\ ${ }^{1}$ Department of Earth and Environmental Sciences, University of Milano-Bicocca, P.zza della \\ Scienza 1, 20126 Milan, Italy \\ 2 Paul Scherrer Institute (PSI), CH-5232 Villigen, Switzerland \\ ${ }^{3}$ Department of Chemistry, University of Turin, Via P. Giuria 5, 10125 Turin, Italy
}

Correspondence to: PhD M. G. Perrone, Department of Earth and Environmental Sciences, University of Milano-Bicocca, P.zza della Scienza 1, 20126 Milan, Italy. Phone (+39)-0264482814; E-mail: grazia.perrone@unimib.it

\begin{abstract}
Recent epidemiological evidence support the hypothesis that health effects from inhalation of air particles are governed by more than just particle mass, since specific chemical components have been identified as important contributors to mortality and hospitality admissions.

We studied the chemical composition and the oxidative potential (OP) of total suspended particle (TSP) samples from Milan at two sites with different traffic loads: a site in the low emission zone (LEZ) and a traffic site (TR) outside. Two a-cellular assays; dithiothreitol (OPDTT) and 2',7' dichlorofluorescin (OPDCFH were used to characterize the OP of the soluble fraction of TSP.

TSP samples from LEZ showed significantly lower concentrations of traffic-related chemical components compared to TR. The decrease in the concentrations from TR to LEZ was maximum for EC, with a LEZ/TR ratio of $0.64( \pm 0.18)$, and a significant reduction $(p<0.01)$ was also observed for PAHs (LEZ/TR=0.73 \pm 0.16 ), elements ( $\mathrm{Mn}, \mathrm{Cu}, \mathrm{Zn}, \mathrm{Cd}, \mathrm{Pb}$ : LEZ/TR ranged between 0.64-0.82), $\mathrm{OC}(\mathrm{LEZ} / \mathrm{TR}=0.85 \pm 0.12)$ and $\mathrm{NH}_{4}{ }^{+}(\mathrm{LEZ} / \mathrm{TR}=0.92 \pm 0.07)$.

OP measures, expressed as $\mathrm{OP} / \mathrm{m}^{3}$ or $\mathrm{OP} / \mathrm{mg}$, were comparable between sites both for OPDTT and OPDCFH, thus not showing any significant impact of local traffic on OP values at sites. OPDT and OPDCFH showed contrasting seasonal and daily trends, indicating that the two a-cellular assays gave complementary information on the OP of particles in Milan. The two OP assays resulted to be sensitive to different chemical properties of PM samples. OPDT correlated positively only with Global Radiation (Spearman's $r_{s}=0.38, p<0.05$ ), which could be considered as a proxy for high concentrations of secondary oxidizing organics, while $\mathrm{OP}^{\mathrm{DCFH}}$ was related to various $\mathrm{PM}$ chemical species, mainly correlated with total mass $\left(r_{s}=0.65 ; p<0.01\right.$ ), elements (e.g. Zn, $r_{s}=0.67$; As, $\left.r_{s}=0.65 ; p<0.01\right)$ and the sum of sulfate and nitrate $\left(r_{s}=0.63 ; p<0.01\right)$, a proxy for secondary aerosol.
\end{abstract}


Keywords: Particulate matter; chemical speciation; urban area; redox activity; DTT; DCFH 


\section{Introduction}

Air quality is a serious problem for the effects on population health, mainly in urban areas where anthropogenic activity and sources are concentrated. Northern Italy is a known hotspot for atmospheric pollution levels, and Milan, the biggest city of Northern Italy, is characterized by high PM levels which are often above limit and quality values indicated by the European Union (EU) air quality Directive 2008/50/EC for PM10 and PM2.5 mass concentrations (Perrone et al., 2012).

When speaking about PM pollution, an important parameter beside the PM mass concentration, is the chemical composition of particles, since a relation between physicochemical properties of PM and biological effects induced by particles has been demonstrated (Lippman and Chen, 2009). The chemical composition of PM is influenced both by sources and atmospheric processes and can vary significantly in time and space. Various studies also observed that adverse health effects induced by exposure to PM differ for different sampling periods and sites (Nawrot et al., 2009; Perrone et al., 2013). The induction of oxidative stress by ambient PM is considered to play a central role in driving adverse effects on human health (Araujo et al., 2009). The ability of particle components to participate in a redox cycle has been proposed to be a key mechanism for the generation of ROS (reactive oxygen species) which cause oxidative stress in cellular systems (Nel et al., 2006). The hazard posed by particles cannot be explained by a single parameter, however the redox properties, referred to as the oxidative potential (OP) of particles, are considered to be a promising and integrative metric for assessing the health effects induced by particles, also providing hazard information for risk assessments (Borm et al., 2007). In this context, different a-cellular tests have been developed to measure the OP of PM, and various studies tested a-cellular assays to investigate the oxidative potential of ambient particles (Charrier et al. 2012; Sauvain et al., 2013; Yang et al. 2014). In this work we investigated the variations in the chemical composition and OP of PM samples in the urban area of Milan . In particular we studied the chemical composition and the OP of total suspended particles (TSP) at two different sites in Milan: a site affected by local traffic (TR site), and a site with a reduced impact of traffic within LEZ (LEZ site). The chemical composition of PM was analyzed in detail including: the carbonaceous fraction, inorganic ions, elements, and trace organic compounds. The OP of the soluble fraction of particles was assessed by two different chemical assays (a-cellular methods): the dithiothreitol (DTT) assay and the $2^{\prime}, 7^{\prime}$ dichlorofluorescin (DCFH) assay.

The main aim of our study was to analyze i) temporal and spatial variations in the concentration of PM mass, chemical components and OP across and between the two urban sites; ii) differences in the OP measured by two independent chemical methods, that is OP measured by the DTT (OPDTT) and by the DCFH (OP ${ }^{D C F H}$ ) assay; iii) the relation between the chemical composition of PM samples and their OP, both $\mathrm{OP}^{\mathrm{DTT}}$ and $\mathrm{OP} \mathrm{PCFH}^{\mathrm{B}}$ 
There are few studies which related that many chemical components to the oxidative potential of particles (Janssen et al., 2014; Charrier et al., 2015; Yang et al., 2015).

\section{Material and Methods}

\subsection{The sampling sites}

PM was sampled at 2 locations in Milan, with different traffic loads.

The two sites are: a traffic site (TR), located within the Campus of the University of Milano Bicocca, about 10 meters away from a crossroad (Viale Sarca-Viale Chiese; traffic flux $\cong$ 33000 vehicles day ${ }^{-1}$ ); a limited traffic site in the city centre within the low emission zone (LEZ) (Figure 1). The LEZ site was located in the courtyard of the National Museum of Science and Technology "Leonardo da Vinci", at a distance of about 15 meters away from the traffic road Via San Vittore, where the traffic flux is $\cong 15000$ vehicles day $^{-1}$ (traffic data from AMAT Agenzia Mobilità Ambiente Territorio, www.amat.mi.it ). LEZ in Milan (known as "Area C") restrict certain vehicles entering in the historic city center. The activation is during all weekdays from 7.30 to $19.30 \mathrm{~h}$ (Thursday from 7.30 to $18.00 \mathrm{~h}$ ). During the activation time, the access to the LEZ is forbidden to Euro 0 gasoline, Euro 0, 1, 2, 3 diesel vehicles, vehicles with a length more than 7,5 meters, and it is regulated by the payment of the congestion charge for other vehicles.

(approximate location of Figure 1)

\subsection{Particle sampling}

The sampling campaigns were conducted during 2013 in 3 seasonal periods at the TR site: 16th-24th January, 8th-18th July, 2th-15th October. During January and July daily samples (24 h) of PM were collected. In October, the sampling was simultaneously performed at both sites during working days from 8.00 to $18.00 \mathrm{~h}$ (daytime 10-hour sampling), when traffic limitation inside the LEZ was implemented.

PM samples were taken using two identical high-volume samplers ( $200 \mathrm{I} \mathrm{min}^{-1}, \mathrm{ECHO}-\mathrm{PUF}$, TCR Tecora, Milan, Italy), collecting the total suspended particles (TSP) on a quartz fiber filter (QFF; diameter $102 \mathrm{~mm}$; Whatman, USA; baked at $600^{\circ} \mathrm{C}$ for $2 \mathrm{~h}$ to reduce the impurities). Before and after sampling, filters were equilibrated ( $48 \mathrm{~h}$ at $35 \% \mathrm{RH}$, ambient $\mathrm{T})$ and weighed with a microbalance (10 $\mu$ g precision) in order to measure ambient TSP concentration (unit: $\mu \mathrm{g} \mathrm{m}^{-3}$ ). All sampled filters were kept in the dark at $-20^{\circ} \mathrm{C}$ (to avoid photo-degradation and evaporation) until the chemical and oxidative potential analysis. In order to guarantee the quality of the PM measurements and analysis, totally six blank field filters were used during these campaigns ( 2 In January, 2 in July and 2 in October).

\subsection{Sample preparation}


Quartz filters were cut in punches to perform all the analyses. Four punches were used to perform the following chemical analysis: ion chromatography (IC, spot of $2.5 \mathrm{~cm} \varnothing$ ), gas chromatography coupled to mass spectrometry (GC-MS, spot of $4.5 \mathrm{~cm} \varnothing$ ), thermal optical transmission (TOT; rectangular spot of $1 \times 1.5 \mathrm{~cm}^{2}$ ) and inductively coupled plasma mass spectrometry (ICP-MS; spot of $2.5 \mathrm{~cm} \varnothing$ ). Two punches (spot of 2.5 and $1.1 \mathrm{~cm} \varnothing$ each) of each filter were cut for OP measurements: DTT and DCFH assay.

\subsection{Chemical analysis}

PM samples were analysed for EC/OC, inorganic ions, elements and trace organic compounds: carboxylic acids, alkylamines, $\mathrm{PAHs}$ and $\mathrm{n}$-alkanes. The methods of chemical analysis are describe below, and further information is provided under Supplemental Material. EC and OC were quantified by means of an EC/OC carbon analyzer (Sunset Laboratory Inc., USA) by thermal optical transmission, TOT, using the NIOSH 5040 protocol. Details on methods are given by Birch and Cary (1996).

Inorganic ions (cations: $\mathrm{Na}^{+}, \mathrm{NH}_{4}{ }^{+}, \mathrm{K}^{+}, \mathrm{Mg}^{++}$and $\mathrm{Ca}^{++}$; anions: $\mathrm{F}^{-}, \mathrm{Cl}^{-}, \mathrm{NO}_{3}{ }^{-}, \mathrm{SO}_{4}{ }^{2-}$ ), carboxylic acids (C1-C5 mono and dicarboxylic acids) and alkylamines (metyil and ethil amines) were determined by extracting filters (spots of $2.5 \mathrm{~cm} \varnothing$ ) under sonication in ultrapure water (18.2 M $\Omega \mathrm{cm}-1$ Milli-Q water system, Millipore, Billerica, MA, USA).The extract was then filtered ( $0.45 \mu \mathrm{m}$ pore size PTFE filter, Alltech USA) and analysed by IC (ICS-2000, Dionex) with a conductivity detector (Perrone et al., 2013).

For PAHs and $n$-alkanes, filters were extracted using dichloromethane: the extract was then filtered, evaporated (under $\mathrm{N}_{2}$ ) and dissolved in isooctane for GC-MS analysis (GC 6850; MS 5973, Agilent), as described in detail in our previous papers (Perrone et al., 2012). 12 PAHs were determined: benzo[a]anthracene (BaA), cyclopenta[cd]pyrene ( $\mathrm{CPcdP})$, chrysene $(\mathrm{CHR})$, benzo[b+j]fluoranthene $(\mathrm{BbF}+\mathrm{BjF})$, benzo[k]fluoranthene (BkF), benzo[e]pyrene (BeP), benzo[a]pyrene (BaP), dibenzo[a,h]anthracene (DBahA), indeno[1,2,3-cd]pyrene (IcdP), benzo[ghi]perylene (BghiP), dibenzo[a,e]pyrene (DBaeP). Concentrations of the homologues series from C20 to C32 were quantified for $n$-alkanes (C20-C32).

For elemental characterization, the aerosol-loaded filters (spot $2.5 \mathrm{~cm} \varnothing$ ) were digested by a microwave oven (Milestone, Ethos ONE) according to the current legislation of the European Community in the field of air quality monitoring (UNI 14902:2005). The digestion mixture was composed of sub-boiling $\mathrm{HNO}_{3}$ and ultra-pure $\mathrm{H}_{2} \mathrm{O}_{2}$ (Sigma-Aldrich, St. Louis, MO, USA). The resulting solutions were filtered and diluted to $15 \mathrm{ml}$ with $\mathrm{H}_{2} \mathrm{O}$ MilliQ. All the elements were determined by a magnetic sector inductively coupled plasma mass spectrometer (SF-ICP-MS) Element 2 by Thermo Scientific (Bremen, Germany). For all chemical species measured, the detection limit (DL) was calculated by analyzing the blank field filters, that are filters which were not used in the sampling but handled, extracted and analysed in the same way as the samples. DL values were computed as the mean signal of all analysed blank field filters plus three times the 
standard deviation. Concentrations of different chemical compounds in the ambient PM samples were considered if they were over the obtained $\mathrm{DL}$, otherwise they were indicated as: <DL. Chemical compounds with more than $50 \%$ of ambient data below the DL were not reported.

\subsection{Oxidative potential assays}

The oxidative potential (OP) is defined as a measure of the capacity of PM to oxidize target molecules, i.e. by generating ROS in environments without cells (a-cellular test). Various a-cellular tests exist to assess the oxidative capacity of PM, each with a different sensitivity to the oxidizing compounds. In this study two independent assays, the DTT assay $\left(\mathrm{OP}^{\mathrm{DTT}}\right.$ ) and the DCFH assay (OPDCFH), were used to assess the oxidative potential of the soluble fraction of particles. Particles collected on filters were extracted as described in paragraph 2.5.1 and 2.5.2, and the insoluble fraction was always removed by filtration before the DTT and the DCFH assay.

\subsubsection{DTT method standard procedure}

The DTT assay provides an estimate of the redox activity of a sample based on the ability of redox active compounds in the PM samples to catalyze electron transfers between DTT and oxygen, thereby generating ROS. DTT, a dithiol compound, is the reducing chemical, which shares similarities with cellular reducing species in the biological systems, e.g. glutathione (Held et al., 1996). Briefly, the rate at which DTT is consumed under a standardized set of conditions is monitored, and the rate of DTT consumption is proportional to the concentration of the catalytically active redox-active species in the PM samples. Redox-active compounds catalyze the reduction of oxygen species to superoxide by DTT, which is oxidized to DTT-Disulfide. The remaining DTT is allowed to react with 5,5'-dithiobis-2-nitrobenzoic acid (DTNB), generating 2-nitro-5-thiobenzoic acid (TNB), which is the "colored" species produced in this reaction and has a high molar extinction coefficient $\left(14150 \mathrm{M}^{-1} \mathrm{~cm}\right.$ at $\left.412 \mathrm{~nm}\right)$ in the visible range.

Previous works have successfully applied the DTT assay to estimate the oxidative potential of PM ambient samples, and various DTT method optimizations have been proposed (Charrier et al., 2012; Li et al., 2009; Rattanavaraha et al., 2011).

The standard DTT procedure we followed is described in detail in Supplemental Material. To measure OP of particles by DTT assay, filters (spot of $2.5 \mathrm{~cm} \varnothing ; 0.2-3.8 \mathrm{mg}$ of PM collected on the spot) were extracted in an ultrasonic bath (10 $\mathrm{min})$ in $4 \mathrm{ml}$ methanol (High purity grade $>99.9 \%$., Riedel-de-Haën). The extract was then filtered $(0.45 \mu \mathrm{m}$ pore size PTFE filter, Alltech USA), evaporated (under $\mathrm{N}_{2}$ ) and dissolved in $1.6 \mathrm{ml}$ of $0.1 \mathrm{M}$ phosphate buffer to be treated with the DTT assay. The extraction of filters in methanol was chosen in agreement with a report by Yang et al. (2014). Yang et al. (2014) and others (Verma et al., 2012; Rattanavaraha et al., 2011), found that for ambient PM samples the methanol extracts produce significantly higher DTT reactivity than the water extracts, suggesting that the use of methanol to retrieve DTT reactive components might be more 
efficient than using water because of methanol extraction properties for both hydrophilic compounds and hydrophobic organic compounds.

\subsubsection{DCFH method standard procedure}

The DCFH assay is commonly used for visualizing ROS generation at a cellular level but has also been used for determining the OP of PM as a-cellular assay (Fuller et al., 2014; King and Weber, 2013; Sauvain et al., 2013; Venkatachari 2007 and 2005). In the DCFH assay, the presence of oxidizing species is assessed from the rapid oxidation of DCFH to a fluorescent compound (DCF). In the presence of horseradish peroxidase (HRP), the test reaches a high sensitivity of $\sim 1.1 \mathrm{nmol} / \mathrm{m}^{3}$ calibrated with a known concentration of $\mathrm{H}_{2} \mathrm{O}_{2}$. Our protocol followed the method of King and Weber (2013) to measure the filters with some modifications, as we describe in Supplemental Material

Filters (spot of $1.1 \mathrm{~cm} \varnothing$ ) were dissolved in $3 \mathrm{ml}$ ultra-pure water for $15 \mathrm{~min}$ at $30^{\circ} \mathrm{C}$. Then the vial was vortexed (Vortex Genie 2, Bender\& Hobein AG, Switzerland) for $1 \mathrm{~min}$ and filtered through a $0.45 \mu \mathrm{m}$ nylon membrane filter (Infochroma, Switzerland). The filtered water extract was diluted to $15 \mathrm{~mL}$ and then analysed by DCFH assay.

\subsection{Data analysis}

We compared the chemical species concentrations and OP values measured the same sampling days (1-15 October) at the TR and LEZ site in Milan to evaluate whether there were significant spatial variations between the two urban sites (paragraph 4.2). We calculated average concentrations at TR and LEZ, and significant differences $(p<0.05)$ were assessed by Student's t test. Also we calculated daily ratios between the two sites (LEZ/TR) for OP values and chemical components, and the mean ratios were tested to see if they were statistically $(p<0.01$ or $p<0.05)$ different from 1 . The day-to-day correlation of $O P$ values and chemical species concentrations for the two sampling sites was assessed by using the Pearson coefficient of determination $\left(R^{2}\right)$.

We attempted to identify relations between OP and other variables, including chemical composition (paragraph 4.4). Therefore, univariate correlations between OP values $\left(\mathrm{OP} / \mathrm{m} 3\right.$ both $\mathrm{OP} \mathrm{DTT}^{\mathrm{D}}$ and $\left.\mathrm{OP}{ }^{\mathrm{DCFH}}\right)$ and meteorological variables, gas pollutant concentrations, $\mathrm{PM}$ mass concentrations and PM species concentrations were calculated using Spearman rank correlation coefficients $\left(r_{s}\right)$, whereby $p<0.01$ or $p<0.05$ were considered statistically significant.

\section{Results and discussion}




\subsection{PM Chemical composition}

Table 1 presents average values and standard deviation of for the TSP mass concentration, carbonaceous fraction (OC, EC and total carbon, TC), elements, inorganic ions, carboxylic acids, alkylamines, PAHs, n-alkanes, some meteorological parameters and gas pollutants separately for the different seasons (winter (W), summer (SU) and late summer (late-SU)) and sites. Meteo data (Global radiation, $\mathrm{T}, \mathrm{RH})$ and gas pollutant $\left(\mathrm{O}_{3}\right.$ and $\mathrm{NO}_{\mathrm{x}}$ ) concentrations were obtained from the Lombardy Regional Agency for Environmental Protection, ARPA stations (ARPA, 2015).

TSP concentrations were 2 times higher in $\mathrm{W}\left(129 \pm 60 \mu \mathrm{g} \mathrm{m}^{-3}\right)$ compared to SU and lateSU when similar TSP concentrations of $50 \pm 7 \mu \mathrm{g} \mathrm{m}^{-3}$ (SU) and $57 \pm 19 \mu \mathrm{g} \mathrm{m}^{-3}$ (late-SU) were measured at the TR site. By comparing our TSP measures with data derived from ARPA stations for PM10 (the fraction of particles $<10 \mu \mathrm{m} \mathrm{d}_{\mathrm{ae}}$, also known "PM respirable fraction"), we calculated that PM10 was the major fraction $(75 \pm 5 \%)$ of TSP samples in all seasons and at both sites in Milan.

The major chemical components of PM were OC (also converted to OM, organic matter, as $1.6^{*} \mathrm{OC}$; Turpin and $\mathrm{Lim}, 2001$ ), $\mathrm{EC}, \mathrm{SO}_{4}{ }^{2-}, \mathrm{NO}_{3}{ }^{-}, \mathrm{NH}_{4}{ }^{+}$and mineral dust (estimated by measurements of elements including $\mathrm{Al}, \mathrm{Ca}, \mathrm{Mg}, \mathrm{Fe}, \mathrm{K}$; Putaud et al., 2010). These single chemical components accounted on average $26 \%(\mathrm{OM}), 4.1 \%(\mathrm{EC}), 6.8 \%\left(\mathrm{SO}_{4}{ }^{2-}\right), 16.6 \%$ $\left(\mathrm{NO}_{3}{ }^{-}\right), 6 \%\left(\mathrm{NH}_{4}{ }^{+}\right)$and $15 \%$ (mineral dust) of TSP, summing up to $\cong 75 \%$ of particle mass. The chemical composition we analyzed for TSP in Milan is consistent with that of the PM10 fraction in Milan (Perrone et al., 2012; Vecchi et al., 2008), as well as that reported by Putaud et al. (2010) for other urban sites across Southern Europe (contributions to PM10 mass: $\mathrm{OM}=26 \%$; $\mathrm{EC}=6 \%$; $\mathrm{SO}_{4}{ }^{2-}=12 \%$; $\mathrm{NO}_{3}{ }^{-}=9 \%$; mineral dust=21\%).

The concentrations (Table 1 and Table S1) of primary trace organic compounds, PAHs and n-alkanes, were similar to previous measurements in Milan in the years 2006-2009 (Perrone et al., 2012), while in the present study we found higher concentrations of carboxylic acids, which are typically attributed to secondary sources. The average concentration of carboxylic acids at the TR site was at a maximum in SU ( $\Sigma C A s=0.96 \pm 0.29$ $\left.\mu \mathrm{g} \mathrm{m}^{-3}\right)$. This was quite high if compared with other summer campaigns in Milan in the years 2006-2009, when the average concentration of $\Sigma$ CAs was $0.47 \pm 0.07 \mu \mathrm{g} \mathrm{m}^{-3}$ for PM10 samples (Perrone et al., 2012). This could indicate an important contribution of secondary organics in the PM samples during this summer 2013 campaign.

In the present study we measured for the first time in Milan the concentrations of alkylamines, of which we found at low but detectable concentrations $\mathrm{DMA}^{+}\left(0.04 \mu \mathrm{g} \mathrm{m}^{-3}\right.$ in SU; 0.09-0.10 $\mathrm{g} \mathrm{m} \mathrm{m}^{-3}$ in W and late-SU) and TEA ${ }^{+}\left(0.36-0.42 \mu \mathrm{g} \mathrm{m}^{-3}\right.$ in late-SU). Despite the very important role that these alkylamines are supposed to play in aerosol chemistry and secondary formation, there are still very few data about their concentrations in PM ambient samples (Ge et al., 2011).

(approximate location of Table 1) 


\subsection{OP of particles, measured as $O \mathrm{P}^{\mathrm{DTT}}$ and $\mathrm{OP} \mathrm{P}^{\mathrm{DCFH}}$}

The OP of the soluble fraction of PM samples was assessed by two different chemical methods, $\mathrm{OP}^{\mathrm{DTT}}$ and $\mathrm{OP} \mathrm{DCFH}$. Both $\mathrm{OP}{ }^{\mathrm{DTT}}$ and $\mathrm{OPDCFH}$ are an estimate of the oxidative potential of PM samples which vary because of different physico-chemical properties of particles. OPDTT and OPDCFH make use of a different reducing agent, DTT and DCFH respectively, to assess the redox activity of a PM sample. Thus, both assays can respond in a different way to redox active compounds in the sample (Sauvain et al., 2013). $\mathrm{OP}^{\mathrm{DTT}}$ and $\mathrm{OPDCFH}$ results are reported expressed with two metrics, OP per $\mathrm{m}^{3}$ air $\left(\mathrm{OP} / \mathrm{m}^{3}\right)$ as well as per $\mathrm{mg} P M(\mathrm{OP} / \mathrm{mg})$. OP values are compared between seasons and sites for each $\mathrm{OP}$ assay. In addition, $\mathrm{OP}{ }^{\mathrm{DTT}}$ and $\mathrm{OP}^{\mathrm{DCFH}}$ results can be compared between them for trends by the same metric $(\mathrm{OP} / \mathrm{m} 3$ or $\mathrm{OP} / \mathrm{mg})$. However, we suggest that $\mathrm{OP}{ }^{\mathrm{DTT}}$ and $\mathrm{OP} \mathrm{PCFH}^{\mathrm{B}}$ are not directly comparable for absolute values, as they indeed use different measuring methods and units $\left(\mathrm{OP}{ }^{D T T}=\right.$ the rate of DTT consumption in time; $\mathrm{OP}{ }^{\mathrm{DCFH}}=$ the total $\mathrm{H}_{2} \mathrm{O}_{2}$ equivalent consumption of DCFH).

Both methods to determine the OP showed a significant inter-day variability of oxidative potential of particles in Milan, expressed as OP/m $\mathrm{m}^{3}$ and $\mathrm{OP} / \mathrm{mg}$ (Figure 2). Despite the daily variability, $\mathrm{OP}{ }^{\mathrm{DTT}}$ and $\mathrm{OP}{ }^{\mathrm{DFCH}}$ clearly showed a seasonal behavior, as reported in Table 2 , which summarizes average values of $\mathrm{OP}^{\mathrm{DTT}}$ and $\mathrm{OP}{ }^{\mathrm{DFCH}}$ for each season and site. $\mathrm{OPDTT} / \mathrm{m}^{3}$ was $0.04( \pm 0.03)$ in $\mathrm{W}, 0.10( \pm 0.05)$ in SU and $0.15( \pm 0.06)$ in late-SU at the TR site. Thus, SU and late-SU samples showed 2-3 times higher $\mathrm{OP}$ DTT $/ \mathrm{m}^{3}$ values as compared to winter. This seasonal trend was even more pronounced when expressed per mg PM. $\mathrm{OP}^{\mathrm{DTT}} / \mathrm{mg}$ was significantly lower in $\mathrm{W}(0.33 \pm 0.18)$ compared to SU $(1.92 \pm 1.07)$ and late$\mathrm{SU}(3.43 \pm 2.94)$. OPDCFH $/ \mathrm{m}^{3}$ showed an opposite seasonal trend with 2 times higher values in W $(0.36 \pm 0.07)$ as compared to SU $(0.14 \pm 0.07)$ at TR. However, when expressed per $\mathrm{mg} \mathrm{PM}, \mathrm{OP}^{\mathrm{DCFH}} / \mathrm{mg}$ values did not significantly differ between seasons, ranging from 2.73 $( \pm 1.29)$ in SU to $4.02( \pm 1.77)$ in late-SU.

The OP of PM in Milan was investigated earlier by Daher et al., (2012) but only with the $\mathrm{DCFH}$ assay. They reported the highest $\mathrm{OP} \mathrm{DCFH} / \mathrm{m}^{3}$ during January-February, which was $2-3$ times higher than in summer, similarly to our results for $\mathrm{OPDCFH} / \mathrm{m}^{3}$.

Instead, a higher OPDTT in summer as compared to winter was found by Charrier et al. (2012) at an urban site in Fresno, CA, the same as the seasonal trend of OPDTT we observed in Milan.

Values of OP of particles in Milan are similar to that reported for other urban sites all over the world. The average $\mathrm{OP}^{\mathrm{DCFH}}$ content of $0.22 \mathrm{nmol} / \mathrm{m}^{3}$ in Milan is comparable to many other publications using the DCFH assay to measure ROS concentrations in ambient PM. For example, $\mathrm{OP} \mathrm{PCFH}^{\mathrm{DCF}} 0.16 \mathrm{nmol} / \mathrm{m}^{3}$ in spring 2012, in Georgia, southeastern United States (King et al., 2013), $0.058 \mathrm{nmol} / \mathrm{m}^{3}$ in aerosol particles collected at a sidewalk in Taipei (Hung and Wang, 2001), $1.2 \mathrm{nmol} / \mathrm{m}^{3}$ in January and February 2004 in Flushing, New York (Venkatachari, et al., 2007), up to $0.38 \mathrm{nmol} / \mathrm{m}^{3}$ in Los Angeles during summer 
2001 (Hasson, et al., 2003), $0.1 \mathrm{nmol} / \mathrm{m}^{3}$ in Summer 2003, in Rubidoux, Riverside county California (Venkatachari et al., 2005).

We found that OP values measured at two sites in Milan were similar (Table 2), whether $\mathrm{OP}$ results are expressed as $\mathrm{OP} / \mathrm{m} 3$ and $\mathrm{OP} / \mathrm{mg}$, thus not evidencing any significant changes in the OP of particles collected at two sites of the same urban area. This is discussed in more detail in the next paragraph 3.3.

(approximate location of Figure 2)

(approximate location of Table 2)

\subsection{Comparison of TR and LEZ sites}

All the parameters were assessed for significant differences between the two sites by the Student's t-test (Table S2). The average concentrations at the two sites were comparable for $\mathrm{PM}$ mass concentration, $\mathrm{OP}$ values (both $\mathrm{OP}{ }^{\mathrm{DTT}}$ and $\mathrm{OP}^{\mathrm{DCFH}}$ ) and the concentration of most chemical compounds. The only exceptions were EC, two elements ( $\mathrm{Cu}$ and $\mathrm{Zn}$ ) and one PAH ( $\mathrm{CHR}$ ) with $\mathrm{p}<0.05$. The average concentrations of $\mathrm{EC}, \mathrm{Cu}, \mathrm{Zn}$ and $\mathrm{CHR}$ were significantly lower at the LEZ site. This can be explained by the reduced impact of traffic emissions at the LEZ site since EC, as well as PAHs and some elements are typical for traffic exhaust and not-exhaust emissions (Perrone et al., 2012).

The day-to-day correlation of measurements between the two sampling sites was assessed by using the Pearson coefficient of determination $\left(R^{2}\right)$ (Table S2). Concentrations of daily PM mass $\left(R^{2}=0.75\right)$ as well as of most chemical compounds were well correlated. In particular, daily concentrations of all major chemical components of $\mathrm{PM}\left(\mathrm{OC}, \mathrm{NH}_{4}{ }^{+}\right.$, $\left.\mathrm{NO}_{3}{ }^{-}, \mathrm{SO}_{4}{ }^{2}\right)$ were highly correlated $\left(\mathrm{R}^{2}=0.83-0.99\right)$ between sites, indicating that the daily variations of the major chemical species and PM mass were strongly influenced by day-today variations over the wider urban area of Milan, due to daily variations of both atmospheric conditions and widespread sources. A somewhat lower correlation between the two sites was found for other chemical compounds, which could be explained by the influence of time-varying local source characteristics, as variations in the local traffic source (e.g. $E C, R^{2}=0.64$ ) and local resuspension (e.g. $\mathrm{Fe}, \mathrm{Ba}, \mathrm{Al}, \mathrm{Ca}, \mathrm{R}^{2}=0.54-0.24$ ) at each site. The very low correlation between sites for some chemical compounds was either caused by very low measured values and/or values below the DL (e.g. Gd, Ni, Co). Daily $\mathrm{OP}$ values were highly correlated for $\mathrm{OP}^{\mathrm{DTT}}\left(\mathrm{R}^{2}\right.$ was 0.69 and 0.91 for $\mathrm{OP} \mathrm{PTT}^{\mathrm{DT}} / \mathrm{m}^{3}$ and $\mathrm{OP}^{\mathrm{DTT}} / \mathrm{mg} \mathrm{PM}$, respectively) and $\mathrm{OP} \mathrm{DCFH} / \mathrm{m}^{3}\left(\mathrm{R}^{2}=0.63\right)$, while the correlation was low for $\mathrm{OPDCFH} / \mathrm{mg}\left(\mathrm{R}^{2}=0.13\right)$. 
Figure 3 pictures the ratios between sites (LEZ/TR), calculated from daily values for OP $\left(\right.$ per $\mathrm{m}^{3}$ ), PM mass and chemical species concentrations (results are also reported in Supplementary Material, Table S2). A ratio LEZ/TR $<1$ indicates that daily concentrations measured at LEZ were lower than those measured at TR. The lowest average ratios, LEZ/TR<0.8, were for Cu (0.64), EC (0.64), followed by $\Sigma 11$ PAHs, most elements ( $\mathrm{Zn}, \mathrm{Pb}$, $\mathrm{Mo}, \mathrm{Ba}, \mathrm{Fe}, \mathrm{Mn})$, and TC. All these chemical components were significantly lower at the LEZ site $(p<0.01$ or $p<0.05$; the only exception was Ba because of a high standard deviation). In addition significant differences ( $p<0.01)$ were also found for $\mathrm{Cd}(0.82)$, OC $(0.85)$ and $\mathrm{NH}_{4}{ }^{+}(0.92)$ (Figure 3 ). The lowest LEZ/TR values $(<0.8)$ were observed for chemical species which are associated to local traffic sources. These species were on average $20-41 \%$ lower at the TR site because of the reduced traffic density at LEZ. For example, the daily EC concentration at the LEZ site was $36 \%$ lower. A previous study performed in Milan in 2009 to assess differences between sites placed in and out the LEZ area, reported for the soot carbon fraction (measured as BC), even differences of $47-61 \%$ between sites within and outside the low emission zone (Invernizzi et al., 2011).

On the other hand, chemical components which were not directly emitted from traffic (secondary formation) or had other sources showed comparable concentrations

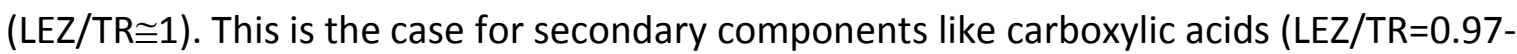
1.10), alkylamines ( $L E Z / T R=1.09-1.17$ ), sulphates ( $L E Z / T R=1.13)$, nitrates ( $L E Z / T R=0.92$ ), as well as for species from other primary sources such as $\mathrm{Al}, \mathrm{Ca}$ and $\mathrm{Ca}^{++}(\mathrm{LEZ} / \mathrm{TR}=0.98-1.06)$ mainly from dust resuspension and $\mathrm{K}^{+}(\mathrm{LEZ} / \mathrm{TR}=0.91)$ also from biomass burning (Perrone et al., 2012).

The OP of PM was comparable for both OPDTT (LEZ/TR=1.07) and OPDCFH (LEZ/TR=0.91). Janssen et al. (2014) found higher OP at a busy traffic site compared to the urban background, thought the difference was not large for OPDT contrary to other OP measures.

The fact that daily OP values, both $\mathrm{OP} \mathrm{PTT}^{\mathrm{DT}}$ and $\mathrm{OP} \mathrm{PCFH}^{\mathrm{DCH}}$ (expressed as $\mathrm{OP} / \mathrm{m}^{3}$ and $\mathrm{OP} / \mathrm{mg}$ ), were comparable at sites and correlated (especially OP ${ }^{\mathrm{DTT}}$ ), means that we did not observe any evidence of the impact of local traffic source on the OP values measured at sites. It would also indicate that day-to-day variations of OP observed at both sites were more influenced by, and thus representative of, values of the oxidative potential of PM over the wider Milan urban area.

(approximate location of Figure 3)

\subsection{Correlation between OP and PM chemical constituents}

We assessed the correlation between OP values (OP/m $3 \mathrm{~m}^{3}$, both $\mathrm{OP}{ }^{\mathrm{DTT}}$ and $\mathrm{OPDCFH}$ ) and meteo variables (Global Radiation, $\mathrm{T}, \mathrm{RH}$ ), gas pollutant concentrations $\left(\mathrm{O}_{3}\right.$ and $\mathrm{NO}_{x}$ ), $\mathrm{PM}$ mass concentration (TSP) and PM composition using the Spearman correlation coefficient $\left(r_{s}\right)$ (Table 3). 
OPDTT showed only for Glob Rad $\left(r_{s}=.0 .38\right)$ a significant $(p<0.05)$ positive correlation. Low positive correlations also revealed $\mathrm{T}, \mathrm{O}_{3}$ and few $\mathrm{PM}$ chemical constituents, including $\mathrm{Ni}$, $\mathrm{SO}_{4}{ }^{2-}$, acetic and oxalic acid. However, $\mathrm{OP}^{\mathrm{DTT}}$ was negatively correlated with most chemical constituents and the highest anti-correlation was observed for $\mathrm{Gd}, \mathrm{Nd}, \mathrm{Mo}, \mathrm{Pb}$ (Spearman's $r$ ranking between -0.69 and $-0.52 ; p<0.01$ ), other metals and alkanes ( $\mathrm{V}, \mathrm{Cd}$, $\mathrm{Fe}, \mathrm{Zn}, \mathrm{Ce}$ and $\Sigma \mathrm{C} 20-\mathrm{C} 32$ : Spearman's $r$ ranking between -0.46 and $-0.40 ; p<0.05)$. $\mathrm{OPDCFH}\left(\mathrm{nmol} / \mathrm{m}^{3}\right)$ showed a positive correlation with the PM mass concentration $\left(r_{s}\right.$ $=0.65 ; p<0.01$ ) in agreement with many other previous studies on this topic (Araujo et al., 2009; Saffari et al., 2013; Daher et al., 2014). OPDCFH also showed a positive correlation with the major chemical components of particles including OC, $\mathrm{TC}, \mathrm{SO}_{4}{ }^{2-}, \mathrm{NO}_{3}{ }^{-}$and $\mathrm{NH}_{4}{ }^{+}\left(\mathrm{r}_{\mathrm{s}}\right.$ $=0.49-0.57 ; p<0.01)$. Sulfate and nitrate do not react with DCFH. Both of those compounds are formed by photochemical reactions and are therefore indicative of oxidative compounds which have been concurrently produced. The Spearman rank of the correlation of $\mathrm{OP}{ }^{\mathrm{DCFH}}$ with the sum of sulfate and nitrate reaches even a high 0.63 . OPDFH was also positively correlated with the metals $\mathrm{Ca}, \mathrm{Mn}, \mathrm{Co}, \mathrm{Zn}$ and $\mathrm{As}$ ( $\mathrm{r}_{\mathrm{s}}=0.50-0.67$; $\mathrm{p}<0.01)$, and to a lesser extent with $\mathrm{Al}, \mathrm{Cu}, \mathrm{Cd}, \mathrm{Gd}, \mathrm{F}^{-}$and $\mathrm{Ca}^{++}\left(r_{s}=0.36-0.44 ; p<0.05\right)$. The different responses of OPDTT and OPDCFH indicate that the DTT and DCFH assays are sensitive to different chemical properties of PM samples.

OPDTT positively correlated mainly with Global Radiation and, to a lesser and low extent, also with $\mathrm{T}, \mathrm{O}_{3}$ and chemical components formed by photochemical reactions $\left(\mathrm{SO}_{4}{ }^{2-}\right.$ and oxalic acid). Global Radiation and all the meteo-chemical variables which were positively related with $\mathrm{OP}{ }^{\mathrm{DTT}}$ were high in SU and late-SU, when the highest OPDTT values were measured. Global Radiation is typically associated with a high secondary organic aerosol (SOA) formation, so it could be speculated that the observed positive correlation between $\mathrm{OPDTT}$ and Global Radiation could indicate that the high oxidative potentials measured by the DTT assay are associated to an high SOA content (not measured) of particles on SU and late-SU days, as also discussed in paragraph 3.1 for carboxylic acid concentrations. SOA is rich in oxidized organic compounds, mainly carbonyl compounds and organic acids (Zhang et al., 2004). Sauvain et al., (2013) have shown that the DTT reactivity can result from the thiol oxidation by carbonyl/acidic groups, while these are not reactive with the DCFH assay. Various authors report that the DTT assay positively responds to the presence of SOA in PM samples (McWhinney et al., 2011), as well as to the presence of specific carbonyl compounds such as quinones (Kumagai et al., 2002).

Some studies report that the DTT assay, besides to be sensitive to oxidizing organic compounds, is also sensitive to metal concentrations in ambient PM samples, in particular, as we did, if no EDTA is used in the assay (Charrier et al., 2012). On the contrary, we found that OPDTT was negatively correlated with metal (except $\mathrm{Ni}$ ) concentrations in the samples. We measured only the soluble fraction of particles (PM samples were extracted in methanol for DTT assay) and disregard the insoluble PM fraction (extracted PM samples were filtered before OP tests, both for the DTT and the 
DCFH assay). A recent study showed that dissolved metals such as $\mathrm{Zn}^{2+}$ (but not $\mathrm{Ni}^{2+}$ ) may undergo complexation with DTT thereby stabilizing DTT against oxidation (Sauvain et al., 2013). Such a stabilization of DTT towards oxidation in the presence of soluble metal ions is reported also by Uzu (et al., 2011) in the case of lead-rich particles. Thus, the observed negative correlation between metal concentrations and OPDTT in the Milan samples could be due to this complexation of DTT with metals in solution. Actually, DTT mimics antioxidant molecules (glutathione for example) in biological systems, so it is argued that the occurrence of complexation with metal ions would indicate a removal of antioxidants, thereby depriving the cells of a protection mechanism against oxidation. This would be in agreement with the observed cellular toxicity for example of $\mathrm{ZnO}$ particles, which is attributed to soluble $\mathrm{Zn}^{2+}$ (Xia et al. 2008).

(approximate location of Table 3)

\section{Conclusions}

We analyzed the chemical composition and the OP of PM (TSP samples) in Milan at two sites which were differently impacted by traffic in October 2013: a low emission zone site (LEZ) and a traffic site (TR) outside this zone.

We observed a decrease in the concentrations from TR to LEZ for EC (-36\%), PAHs (-27\%) and some elements (between $-27 \%$ and $-37 \%$ for $\mathrm{Cu}, \mathrm{Zn}, \mathrm{Pb}, \mathrm{Mo}, \mathrm{Ba}, \mathrm{Fe}, \mathrm{Mn}$ ). Such results demonstrate the impact of local traffic source on the concentrations at sites of specific PM chemical components (EC, PAHs and elements) which are known for their adverse health effects on the exposed population. For this reason, such data can also be helpful to policy and decision makers in evaluating the benefits of local traffic reductions in urban areas. As an indicator of adverse health effects of PM we measured the OP of the soluble fraction of TSP samples to get information on the oxidative stress caused by exposure to PM. As TSP concentrations in Milan were mainly PM10 (75\%), and as chemical composition of the two fractions were found similar, in good approximation our OP results for TSP could be an estimate of the OP of PM10, or respirable PM fraction. We used two different a-cellular assays, DTT and DCFH, which are most frequently used to assess the OP of ambient particles. Both methods showed no significant difference in the oxidative potential of particles between the two sites indicating that the OP of PM is mostly influenced by the general conditions over the wider Milan urban area.

A seasonal trend was observed for OP of Milan PM but opposite for the two methods, with maximum $O P^{D T T}$ values (OPDT $\mathrm{m}^{-3}$ and $O P^{D T T} \mathrm{mg}^{-1} \mathrm{PM}$ ) in summer, while $\mathrm{OP}^{\mathrm{DCFH}}$ was highest in winter. The different behavior between the $\mathrm{OP}^{\mathrm{DTT}}$ and $\mathrm{OP}{ }^{\mathrm{DCFH}}$ assay seems to be due to their sensitivity to different chemical properties of PM samples. OPDTT correlated positively with Global Radiation (probably a proxy for high concentrations of secondary organic aerosol, rich in carbonyl compounds which are reactive with DTT) and negatively with metals (because DTT can complex with ion metals inhibiting their reactivity). OPDCFH 
correlated positively with TSP mass, sulfate and nitrate as indicators of secondary produced oxidative species and some metals. The limited data set does not allow to disentangle the contribution of each parameter. In summary it seems both methods indicate an increase in OP with photochemical processes. However, complexing metals may suppress the signal partially in the DTT assay. It is still difficult to say which assay is best suited to evaluate the real oxidative stress caused by PM exposure. It should be considered at least a combination of the DTT and DCFH assays to gain complementary information on the oxidative capacity of particles.

\section{Acknowledgments}

We would like to thank the Museo Nazionale della Scienza e della Tecnica "Leonardo da Vinci" of Milan (www.museoscienza.org) for providing the logistic support during the sampling campaign at LEZ site. We thank Giuseppe Trentacosti who performed the IC analysis during his thesis work. This work was supported by the Swiss National Science Foundation grant no.407040-153970 and the China Scholarship Council.

\section{References}

Araujo J.A., Nel A.E., 2009. Particulate matter and atherosclerosis: Role of particle size, composition and oxidative stress. Particle and Fibre Toxicology 6, 24-43.

Birch M.E., Cary R.A., 1996. Elemental carbon-based method for monitoring occupational exposures to particulate diesel exhaust. Aerosol Science and Technology 25, 221-241.

Borm P.J.A., Kelly F., Kunzli N., Schins R.P.F., Donaldson K., 2007. Oxidant generation by particulate matter: from biologically effective dose to a promising, novel metric. Occupational and Environmental Medicine 64, 73-74.

Charrier J.G., Richards-Henderson N.K., Bein K.J., McFall A.S., Wexler A.S., Anastasio C., 2015. Oxidant production from source-oriented particulate matter- Part 1: Oxidative potential using the dithiothreitol (DTT) assay. Atmospheric Chemistry and Physics 15, 2327-2340.

Charrier J.G, Anastasio C., 2012. On dithiothreitol (DTT) as a measure of oxidative potential for ambient particles: evidence for the importance of soluble transition metals. Atmospheric Chemistry and Physics 12, 9321-9333.

Daher N., Ruprecht A., Invernizzi G., De Marco C., Miller-Schulze J., Heo J.B., Shafer M.M., Shelton B.R., Schauer J.J., Sioutas C., 2012. Characterization, sources and redox activity of fine and coarse particulate matter in Milan, Italy. Atmospheric Environment 49, 130-141.

Daher N., Saliba N.A., Shihadeh A.L., Jaafar M., Baalbaki R., Shafer M.M., Schauer J.J., Soiutas C., 2014. Oxidative potential and chemical speciation of size-resolved particulate matter (PM) at near freeway and urban background sites in the greater Beirut area. Science of The Total Environment 470-471, 417-426. 
Fuller S.J., Wragg F.P.H., Nutter J., Kalberer M., 2014. Comparison of on-line and off-line methods to quantifiy reactive oxygen species (ROS) in atmospheric aerosols. Atmospheric Environment 92, 97-103.

Ge X., Wexler A.S., Clegg S., 2011. Atmospheric amines- Part I. A review. Atmospheric Environment 45, 524-546.

Hasson A.S., Paulson S.E., 2003. An investigation of the relationship between gas-phase and aerosol-borne hydroperoxides in urban air. Journal of Aerosol Science 34, 4, 459-468.

Held K.D., Sylvester F.C., Hopcia K.L., Biaglow J.E., 1996. Role of Fenton chemistry in thiolinduced toxicity and apoptosis. Radiation Research 145, 542-553.

Hung H.F., Wang C., 2001. Experimental determination of reactive oxygen species in Taipei aerosols. Journal of Aerosol Science 32, 1201-1211.

Invernizzi G., Ruprecht A., Mazza R., De Marco C., Mocnik C., Sioutas C., Westerdahl D., 2011. Measurement of black carbon concentration as an indicator of air quality benefits of traffic restriction policies within the ecopass zone in Milan, Italy. Atmospheric Environment 45, 3522-3227.

Lippman M., Chen L.C., 2009. Health effects of concentrated ambient air particulate matter (CAPs) and its components. Critical Reviews in Toxicology 39, 10, 865-913.

Janssen N., Yang A., Strak M., Steenhof M., Hellack B., Gerlofs-Nijland M.E., Kuhlbush T., Kelly F., Harrison R., Brunekreef, B., Hoek G., Cassee F., 2014. Oxidative potential of particulate matter collected at sites with different source characteristics. Science of the Total Environment 472, 572-581.

King L.E., Weber R.J., 2013. Development and testing of an online method to measure ambient fine particulate reactive oxygen species (ROS) based on the 2' -7 'dichlorofluorescin (DCFH) assay. Atmospheric Measurement Techniques 6, 1647-1658.

Kumagai Y., Koide S., Taguchi K., Endo A., Nakai Y., Yoshikawa T., Shimojo, N., 2002. Oxidation of proximal protein sulfhydryls by phenanthraquinone, a component of diesel exhaust particles. Chemical Research in Toxicology 15, 483-489.

Li Q., Wyatt A., Kamens R.M., 2009. Oxidant generation and toxicity enhancement of ageddiesel exhaust. Atmospheric Environment 43, 1037-1042.

McWhinney R.D., Gao S.S., Zhou S., Abbatt J.P.D., 2011. Evaluation of the effects of ozone oxidation and redox-cycling activity of two-stroke engine exhaust particles. Environmental Science and Technology 45, 2131-2136

Nawrot T.S., Kuenzli N., Sunyer J., Shi T., Moreno T., Viana M., Heinrich J., Forsberg B., Kelly F.J., Sughis M., Nemery B., Borm P., 2009. Oxidative properties of ambient PM2.5 and elemental composition: heterogeneous associations in 19 European cities. Atmospheric Environment 43, 4595-4602.

Nel A., Xia T., Madler L., Li, N., 2006. Toxic potential of materials at the nanolevel. Science 311, 622-627.

Perrone M.G., Larsen B.R., Ferrero L., Sangiorgi G., De Gennaro G., Udisti R., Zangrando R., Gambaro A., Bolzacchini E., 2012. Sources of high PM2.5 concentrations in Milan, 
Northern Italy: Molecular marker data and CMB modelling. Science of the Total Environment 414, 343-355.

Perrone M.G., Gualtieri M., Consonni V., Ferrero L., Sangiorgi G., Longhin E., Ballabio D., Bozacchini E., Camatini M., 2013. Particle size, chemical composition, seasons of the year and urban, rural and remote site origins as determinants of biological effects of particulate matter on pulmonary cells. Enviromental Pollution 176, 215-227.

Rattanavaraha W., Rosen E., Zhang H., Li Q., Pantong K., Kamens R.M., 2011. The reactive oxidant potential of different types of aged atmospheric particles: an outdoor chamber study. Atmospheric Environment 45, 3848-3855.

Saffari A., Daher N., Samara C., Voutsa D., Kouras A., Manoli E., Karagkiozidou O., Vlachokostas C., Moussiopoulos N., Shafer M.M., Schauer J.J., Sioutas C., 2013. Increased biomass burning due to the economic crisis in Greece and its adverse impact on wintertime air quality in Thessaloniki. Environmental Science and Technology 47, 13313-13320.

Sauvain J.J., Rossi M.J., Riediker M., 2013. Comparison of three a cellular tests for assessing the oxidation potential of nanomaterials. Aerosol Science and Technology 47:2, 218-227.

Uzu G., Sauvain J.J., Baeza-Squiban A., Riediker M., Sanchez M., Val S., Tack K., Denys S, Pradère $P$, Dumat $C$., 2011. In vitro assessment of the pulmonary toxicity and gastric availability of lead-rich particles from a lead recycling plant. Environmental Science and Technology 45, 7888-7895

Venkatachari P., Hopke P., Brune W.H., Ren X., Lesher R., Mao, J., Mitchell, M., 2007. Characterization of Wintertime Reactive Oxygen Species Concentrations in Flushing, New York. Aerosol Science and Technology 41, 2, 97-111.

Venkatachari P., Hopke P., Grover B.D., Eatough D.J., 2005. Measurement of Particle-Bound Reactive Species in Rubidoux Aerosols. Journal of Atmospheric Chemistry 50, 1, 49-58.

Verma V., Rico-Martinez R., Kotra N., King L., Liu J., Snell T.W., Weber R.J., 2012. Contribution of water-soluble and insoluble components and their hydrophobic/hydrophilic subtractions to the reactive oxygen species-generating potential of fine ambient aerosols. Environmental Science and Technology 46, 11384-11392.

Xia T., Kovochich M., Liong M., Madler L., Gilbert B., Shi H.B., et al., 2008. Comparison of the mechanism of toxicity of zinc oxide and cerium oxide nanoparticles based on dissolution and oxidative stress properties. ACS Nano 2, 2124-2134

Yang A., Hellack B., Leseman D., Brunekreef B., Kuhlbusch T.A.J., Cassee F.R., Hoeck G., Hanssen N.A.H., 2015. Temporal and spatial variation of the metal -related oxidative potential of PM2.5 and its relation to PM2.5 mass and elemental composition. Atmospheric Environment 102, 62-69.

Yang A., Jedynska A., Hellack B., Kooter I., Hoek G., Brunekreef B., Kuhlbusch T.A.J., Cassee F.R., Janssen N.A.H., 2014. Measurement of the oxidative potential of PM2.5 and its constituents: the effect of extraction solvent and filter type. Atmospheric Environment $83,35-42$. 
Zhang R., Suh I., Zhao J., Zhang D., Fortner E.C., Tie X., Molina L.T., Molina J.M., 2004.

Atmospheric New Particle Formation Enhanced by Organic Acids. Science 4, 304, 5676, 1487-1490. 


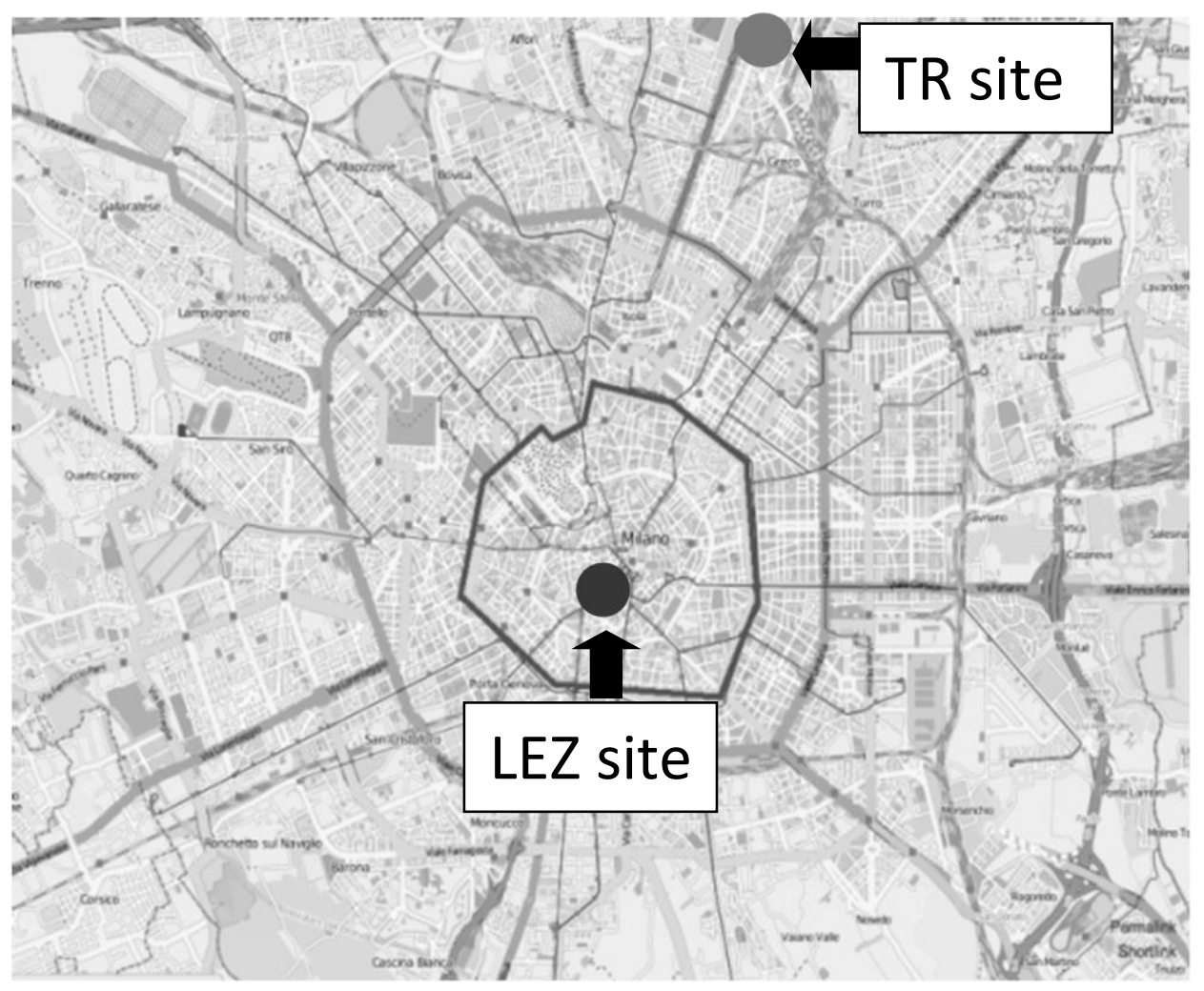

Figure 1 

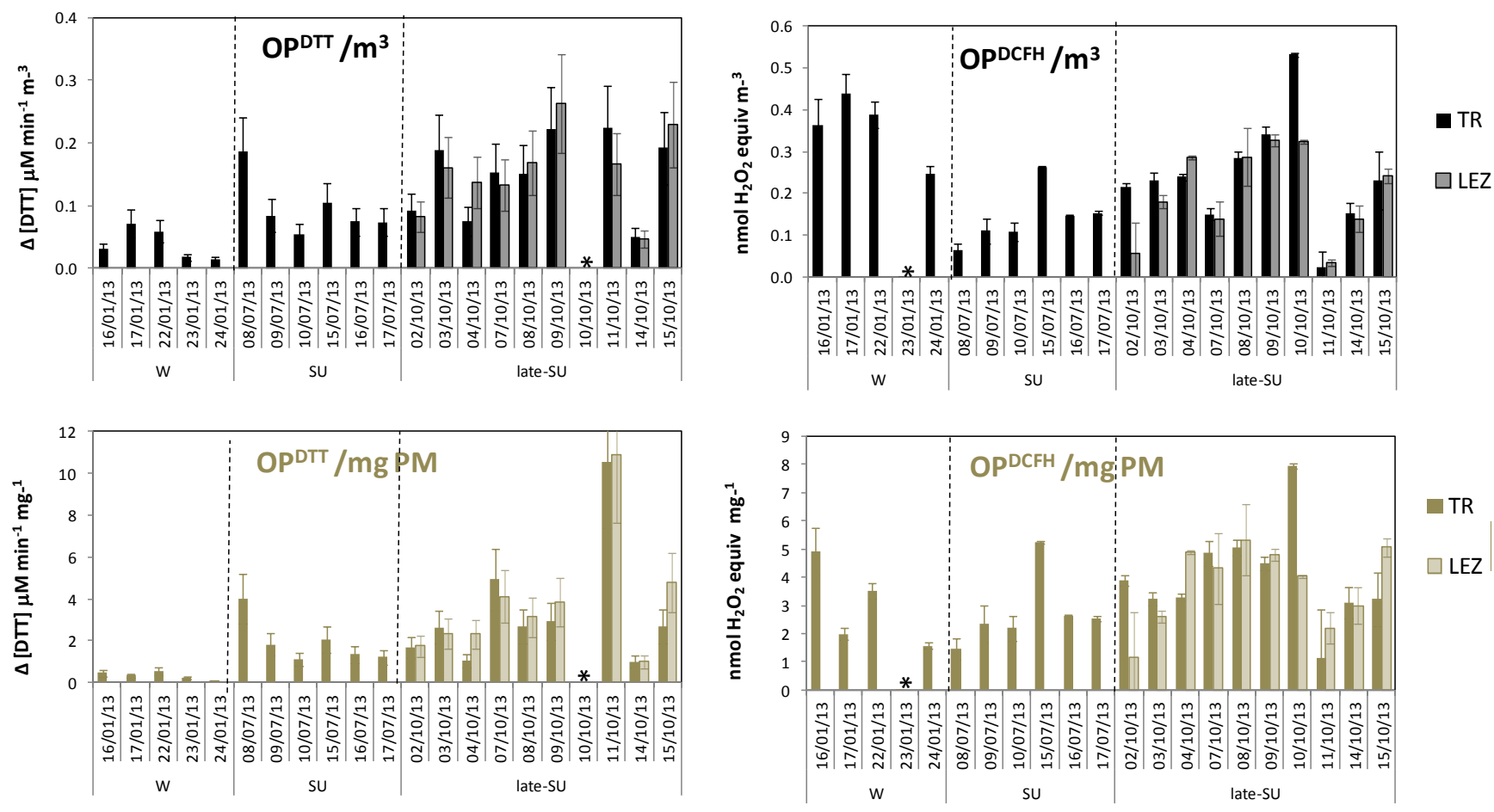

Figure 2 


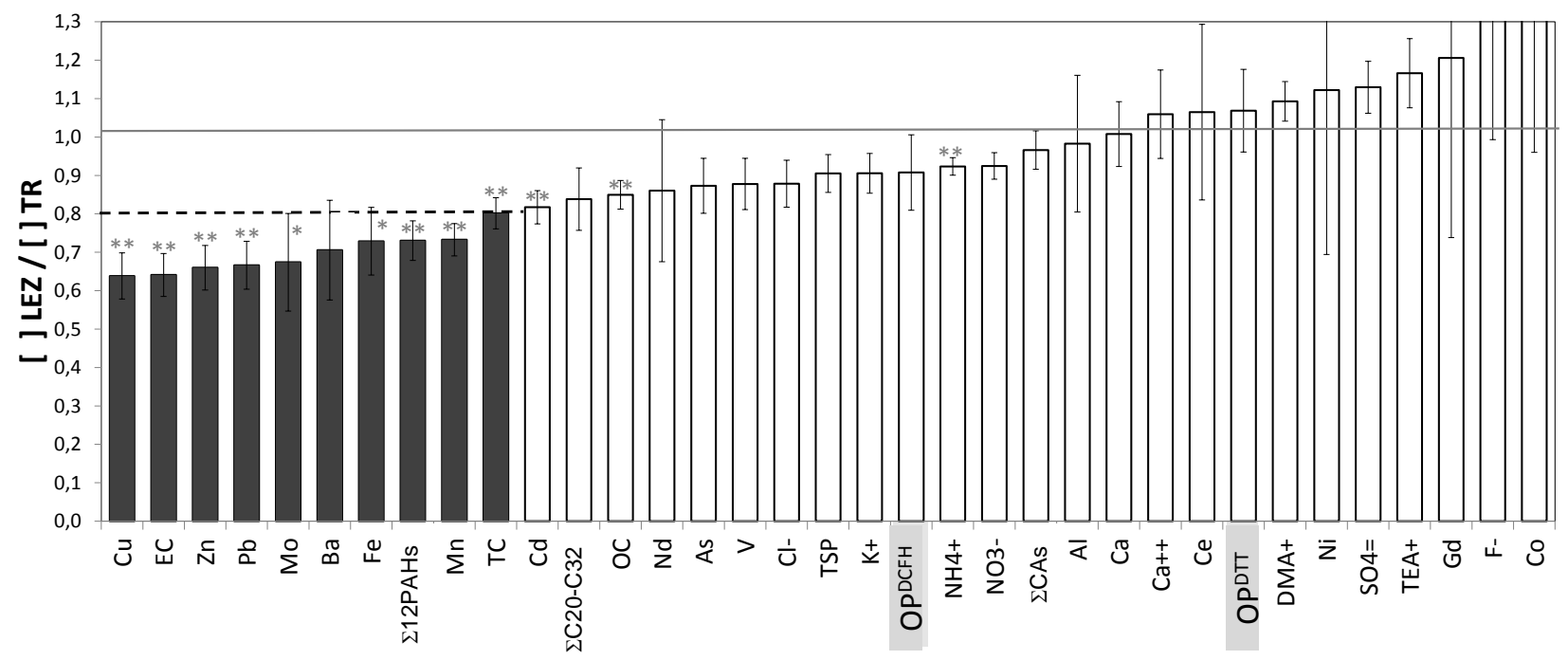

Figure 3 
Figure 1 Map of the city of Milan, with the location of the two sampling sites: the traffic site (TR site) and the site within the low emission zone (LEZ site). The LEZ area is delimited by the dark line in the map.

Figure 2 Oxidative potential ( $\mathrm{OP}^{\mathrm{DTT}}$ and $\mathrm{OP}^{\mathrm{DCFH}}$ ) of the soluble fraction of daily $\mathrm{PM}$ (total suspended particle, TSP) samples in Milan. Values are presented either per $\mathrm{m}^{3}$ air (OP/m $\mathrm{m}^{3}$, top row) or per $\mathrm{mg}$ TSP (OP/mg PM, lower row). ${ }^{*}=$ not measured. Error bars indicate coefficient of variations (CVs) for duplicate measurements.

Figure 3 Average ratios (error bar indicates SD of average) calculated from the daily values $(n=10)$ at the LEZ and $T R$ site for $O P / m^{3}\left(O P^{D T T}\right.$ and $\left.O P^{D C F H}\right), P M$ mass (TSP) and chemical concentrations. Values are in ascending order and dark bars highlight LEZ/TR values $<0.8$. LEZ/TR significantly different from $1:{ }^{*} p<0.05$, $* * p<0.01$. 


\begin{tabular}{|c|c|c|c|c|c|c|c|c|c|c|c|}
\hline & & & & & \multicolumn{5}{|c|}{ Traffic (TR) site } & \multirow{2}{*}{\multicolumn{2}{|c|}{$\begin{array}{c}\text { LEZ site } \\
\text { late summer - lateSU }\end{array}$}} \\
\hline & & & & & \multirow{2}{*}{$\begin{array}{c}\text { winter - W } \\
\text { Jan-Feb } 13 \quad(n=5)\end{array}$} & \multicolumn{2}{|c|}{ summer - SU } & \multicolumn{2}{|c|}{ late summer - lateSU } & & \\
\hline & & & & & & July & $13 \quad(n=7)$ & $1-15$ Oc & ct $13 \quad(n=10)$ & 1-15 Oct & $13 \quad(n=10)$ \\
\hline & & & & & Mean $S D$ & Mean & $S D$ & Mean & $S D$ & Mean & $S D$ \\
\hline \multirow{3}{*}{\multicolumn{3}{|c|}{ Meteo Data ${ }^{(1)}$}} & Global Rad & $W m^{-2}$ & $54 \pm 25$ & 247 & \pm 41 & 158 & \pm 82 & 158 & \pm 82 \\
\hline & & & $\mathrm{T}$ & ${ }^{\circ} \mathrm{C}$ & $4,2 \pm 1,3$ & 25,7 & $\pm 0,8$ & 15,9 & $\pm 1,3$ & 15,9 & $\pm 1,3$ \\
\hline & & & $\mathrm{RH}$ & $\%$ & $78,4 \pm 8$ & 54 & $\pm 3,6$ & 69,9 & $\pm 16,0$ & 69,9 & $\pm 16,0$ \\
\hline \multirow{2}{*}{\multicolumn{3}{|c|}{ Gas pollutants $^{(1)}$}} & NOx & $\mu \mathrm{g} \mathrm{m}^{-3}$ & $160,8 \pm 44$ & 53 & $\pm 5,3$ & 112,5 & $\pm 35,1$ & 108,4 & $\pm 29,7$ \\
\hline & & & 03 & $\mu \mathrm{g} \mathrm{m}^{-3}$ & $8,4 \pm 6$ & 85 & $\pm 10,4$ & 25,2 & $\pm 15,1$ & 20,3 & $\pm 10,0$ \\
\hline \multicolumn{3}{|l|}{ Particulate Matter } & TSP & $\mu \mathrm{g} \mathrm{m}^{-3}$ & $129 \pm 60$ & 50 & \pm 7 & 57 & \pm 19 & 52 & \pm 19 \\
\hline \multirow{34}{*}{$\begin{array}{l}\text { TSP chemical } \\
\text { composition }\end{array}$} & \multirow{3}{*}{\multicolumn{2}{|c|}{$\begin{array}{l}\text { Carbonaceous fraction } \\
\left(\mu \mathrm{g} \mathrm{m}^{-3}\right)\end{array}$}} & OC & & $26,5 \pm 17,5$ & 7,5 & $\pm 0,8$ & 9,0 & $\pm 3,2$ & 7,4 & $\pm 1,9$ \\
\hline & & & EC & & $6,2 \pm 2,9$ & 1,5 & $\pm 0,4$ & 2,6 & $\pm 1,1$ & 1,6 & $\pm 0,6$ \\
\hline & & & $\mathrm{TC}$ & & $32,8 \pm 20,3$ & 9,0 & $\pm 0,9$ & 11,6 & $\pm 4,2$ & 9,0 & $\pm 2,4$ \\
\hline & \multirow{18}{*}{\multicolumn{2}{|c|}{$\begin{array}{l}\text { Elements } \\
\left(\mu \mathrm{g} \mathrm{m}^{-3}\right)\end{array}$}} & $\mathrm{Al}$ & & $0,7 \pm 0,4$ & 0,3 & $\pm 0,1$ & 0,4 & $\pm 0,2$ & 0,4 & $\pm 0,3$ \\
\hline & & & $\mathrm{Ca}$ & & $3,4 \pm 1,8$ & 1,2 & $\pm 0,3$ & 1,9 & $\pm 0,4$ & 1,9 & $\pm 0,5$ \\
\hline & & & v & & $0,0037 \pm 0,0016$ & 0,0017 & $\pm 0,0004$ & 0,0017 & $\pm 0,0008$ & 0,0014 & $\pm 0,0007$ \\
\hline & & & $\mathrm{Mn}$ & & $0,053 \pm 0,023$ & 0,016 & $\pm 0,002$ & 0,022 & $\pm 0,007$ & 0,016 & $\pm 0,006$ \\
\hline & & & $\mathrm{Fe}$ & & $4,2 \pm 2,0$ & 0,9 & $\pm 0,1$ & 1,1 & $\pm 0,6$ & 0,7 & $\pm 0,3$ \\
\hline & & & Co & & $0,0017 \pm 0,0008$ & 0,0004 & $\pm 0,0001$ & 0,0007 & $\pm 0,0008$ & 0,0006 & $\pm 0,0003$ \\
\hline & & & $\mathrm{Ni}$ & & $0,0080 \pm 0,0033$ & 0,0018 & $\pm 0,0004$ & 0,0105 & $\pm 0,0076$ & 0,0119 & $\pm 0,0084$ \\
\hline & & & $\mathrm{Cu}$ & & $0,161 \pm 0,075$ & 0,032 & $\pm 0,009$ & 0,047 & $\pm 0,027$ & 0,026 & $\pm 0,010$ \\
\hline & & & $\mathrm{Zn}$ & & $0,229 \pm 0,129$ & 0,049 & $\pm 0,013$ & 0,064 & $\pm 0,026$ & 0,039 & $\pm 0,009$ \\
\hline & & & As & & $0,0021 \pm 0,0012$ & 0,0009 & $\pm 0,0002$ & 0,0012 & $\pm 0,0005$ & 0,0010 & $\pm 0,0004$ \\
\hline & & & $\mathrm{Cd}$ & & $0,0037 \pm 0,0023$ & 0,0006 & $\pm 0,0003$ & 0,0007 & $\pm 0,0004$ & 0,0006 & $\pm 0,0003$ \\
\hline & & & $\mathrm{Ba}$ & & $0,078 \pm 0,041$ & 0,016 & $\pm 0,005$ & 0,025 & $\pm 0,014$ & 0,016 & $\pm 0,007$ \\
\hline & & & $\mathrm{Ce}$ & & $0,0021 \pm 0,0009$ & 0,0008 & $\pm 0,0001$ & 0,0007 & $\pm 0,0003$ & 0,0006 & $\pm 0,0003$ \\
\hline & & & $\mathrm{Nd}$ & & $0,0006 \pm 0,0004$ & 0,0002 & $\pm 0,0000$ & 0,0002 & $\pm 0,0001$ & 0,0002 & $\pm 0,0002$ \\
\hline & & & $\mathrm{Gd}$ & & $0,00047 \pm 0,00022$ & 0,00014 & $\pm 0,00004$ & 0,00008 & $\pm 0,00005$ & 0,00007 & $\pm 0,00002$ \\
\hline & & & $\mathrm{Pb}$ & & $0,143 \pm 0,081$ & 0,022 & $\pm 0,023$ & 0,016 & $\pm 0,011$ & 0,010 & $\pm 0,005$ \\
\hline & & & Mo & & $0,009 \pm 0,004$ & 0,002 & $\pm 0,001$ & 0,001 & $\pm 0,001$ & 0,001 & $\pm 0,001$ \\
\hline & & & Selements & & $9,019 \pm 4,344$ & 2,574 & $\pm 0,299$ & 2,977 & $\pm 1,465$ & 2,350 & $\pm 1,518$ \\
\hline & \multirow{8}{*}{\multicolumn{2}{|c|}{$\begin{array}{l}\text { Inorganic ions } \\
\left(\mu \mathrm{g} \mathrm{m}^{-3}\right)\end{array}$}} & F- & & $0,08 \pm 0,04$ & 0,02 & $\pm 0,01$ & 0,02 & $\pm 0,02$ & 0,02 & $\pm 0,02$ \\
\hline & & & $\mathrm{Cl}-$ & & $3,7 \pm 3,4$ & 0,1 & $\pm 0,0$ & 0,7 & $\pm 0,8$ & 0,6 & $\pm 0,8$ \\
\hline & & & NO3- & & $16,5 \pm 6,6$ & 5,7 & $\pm 2,2$ & 10,9 & $\pm 6,6$ & 10,2 & $\pm 6,5$ \\
\hline & & & SO4= & & $4,0 \pm 1,5$ & 3,5 & $\pm 0,3$ & 4,2 & $\pm 2,6$ & 4,5 & $\pm 2,6$ \\
\hline & & & $\mathrm{NH} 4+$ & & $3,9 \pm 1,4$ & 2,7 & $\pm 0,4$ & 4,2 & $\pm 2,9$ & 4,0 & $\pm 3,0$ \\
\hline & & & $\mathrm{K}+$ & & $5,56 \pm 2,41$ & 0,27 & $\pm 0,05$ & 0,71 & $\pm 0,74$ & 0,62 & $\pm 0,63$ \\
\hline & & & $\mathrm{Ca}_{++}$ & & $2,6 \pm 1,2$ & 1,6 & $\pm 0,3$ & 1,6 & $\pm 0,7$ & 1,5 & $\pm 0,5$ \\
\hline & & & Lions & & $38,8 \pm 12,5$ & 12,5 & $\pm 4,4$ & 23,3 & $\pm 12,2$ & 23,1 & $\pm 12,2$ \\
\hline & \multicolumn{2}{|c|}{ Carboxylic acids (CAs) ( $\left.\mu \mathrm{g} \mathrm{m}^{-3}\right)$} & $\Sigma$ CAs & & $1,32 \pm 0,53$ & 0,96 & $\pm 0,29$ & 0,75 & $\pm 0,18$ & 0,73 & $\pm 0,21$ \\
\hline & \multirow{2}{*}{$\begin{array}{l}\text { Alkylamines } \\
\left(\mu \mathrm{g} \mathrm{m}^{-3}\right)\end{array}$} & dimethylamine & DMA+ & & $0,10 \pm 0,03$ & 0,04 & $\pm 0,00$ & 0,09 & $\pm 0,02$ & 0,10 & $\pm 0,01$ \\
\hline & & triethylamine & TEA+ & & $<0.32$ & $<0.32$ & & 0,36 & $\pm 0,02$ & 0,42 & $\pm 0,10$ \\
\hline & \multicolumn{2}{|l|}{ PAHs $\left(\mathrm{ng} \mathrm{m}^{-3}\right)$} & $\Sigma$ 12PAHs & & $59,32 \pm 22,46$ & 0,64 & $\pm 0,64$ & 2,43 & $\pm 1,74$ & 1,68 & $\pm 0,95$ \\
\hline & \multicolumn{2}{|c|}{ n-Alkanes (ALKs) $\left(\mathrm{ng} \mathrm{m}^{-3}\right)$} & $\Sigma \mathrm{C} 20-\mathrm{C} 32$ & & $185,03 \pm 144,37$ & 40,31 & $\pm 6,42$ & 50,48 & $\pm 14,88$ & 41,71 & $\pm 19,50$ \\
\hline
\end{tabular}

We took the data from four ARPA stations: "Verziere" and "Senato" stations for the LEZ site; "Marche" and "Senato" stations for the TR site.

Table 1 Meteorological data, gas pollutants $\left(\mathrm{NO}_{\mathrm{x}}\right.$ and $\left.\mathrm{O}_{3} ; \mu \mathrm{g} \mathrm{m}^{-3}\right)$, particulate matter $\left(\mathrm{TSP} \mu \mathrm{g} \mathrm{m}^{-3}\right)$ and chemical species ( $\mu \mathrm{g} \mathrm{m}^{-3}$ or $\mathrm{ng} \mathrm{m}^{-3}$ ) concentrations in TSP samples from the TR site (W, SU and late-SU campaigns) and the LEZ site (late-SU campaign). Mean \pm standard deviation (SD). 


\begin{tabular}{|c|c|c|c|c|c|}
\hline \multirow[b]{3}{*}{ OP measure } & \multirow[b]{3}{*}{ metric } & \multirow[b]{3}{*}{ unit } & \multicolumn{3}{|c|}{ Traffic (TR) site } \\
\hline & & & $\begin{array}{c}\text { winter - W } \\
\text { Jan-Feb } 13 \quad(n=5)\end{array}$ & $\begin{array}{l}\text { summer - SU } \\
\text { July } 13 \quad(n=6)\end{array}$ & $\begin{array}{r}\text { late summ } \\
1-15 \text { Oct } 1\end{array}$ \\
\hline & & & Mean $S D$ & Mean $S D$ & Mean \\
\hline OP ${ }^{\mathrm{DTT}}$ & per unit air & $\Delta[\mathrm{DTT}] \mu \mathrm{M} \min ^{-1} \mathrm{~m}^{-3}$ & $0.04 \pm 0.03$ & $0.10 \pm 0.05$ & $0.15 \pm c$ \\
\hline OP ${ }^{\mathrm{DCFH}}$ & volume $\left(\mathrm{m}^{-3}\right)$ & nmol H2O2 equiv $\mathrm{m}^{-3}$ & $0.36 \pm 0.08$ & $0.14 \pm 0.07$ & $0.24 \pm 0$ \\
\hline$O P^{D T T}$ & per unit PM & $\Delta[\mathrm{DTT}] \mu \mathrm{M} \mathrm{min}^{-1} \mathrm{mg}^{-1}$ & $0.33 \pm 0.18$ & $1.92 \pm 1.07$ & $3.34 \pm 2$ \\
\hline$O P^{\mathrm{DCFH}}$ & $\operatorname{mass}\left(\mathrm{mg}^{-1}\right)$ & $\mathrm{nmol} \mathrm{H} 2 \mathrm{O} 2$ equiv $\mathrm{mg}^{-1}$ & $2.99 \pm 1.52$ & $2.73 \pm 1.29$ & $4.02 \pm 1$ \\
\hline
\end{tabular}

Table 2 Oxidative potential (OP) measured (per volume air, $\mathrm{m}^{-3}$; per PM mass, $\mathrm{mg}^{-1}$ ) in TSP samples from the TR site (W, SU and late-SU campaigns) and the LEZ site (late-SU campaign). Mean \pm standard deviation

(SD) 


\begin{tabular}{|c|c|c|c|c|}
\hline & & & $O P_{D T T}(n=29)$ & $O P_{D C F H}(n=31)$ \\
\hline \multirow{3}{*}{\multicolumn{2}{|c|}{ Meteo data }} & Global Rad & $0,38^{*}$ & $-0,38 *$ \\
\hline & & $\mathbf{T}$ & 0,28 & $-0,17$ \\
\hline & & $\mathbf{R H}$ & $-0,19$ & $0,41 *$ \\
\hline \multirow{2}{*}{\multicolumn{2}{|c|}{$\begin{array}{l}\text { Gas } \\
\text { pollutants }\end{array}$}} & $\mathrm{NO}_{\mathrm{x}}$ & $-0,15$ & 0,25 \\
\hline & & $\mathrm{O}_{3}$ & 0,22 & $-0,22$ \\
\hline \multicolumn{2}{|l|}{$\begin{array}{l}\text { PM total } \\
\text { mass }\end{array}$} & TSP & $-0,15$ & $0,65^{* *}$ \\
\hline \multirow[t]{34}{*}{ PM chemical } & & OC & $-0,30$ & $0,51 * *$ \\
\hline & & EC & $-0,27$ & 0,30 \\
\hline & & TC & $-0,33$ & $0,49 * *$ \\
\hline & & Al & $-0,21$ & $0,41 *$ \\
\hline & & $\mathrm{Ca}$ & $-0,19$ & $0,55 * *$ \\
\hline & & $\mathbf{v}$ & $-0,46 *$ & 0,30 \\
\hline & & $M n$ & $-0,35$ & $0,50 * *$ \\
\hline & & $\mathrm{Fe}$ & $-0,43 *$ & 0,31 \\
\hline & & Co & $-0,22$ & $0,55 * *$ \\
\hline & & $\mathrm{Ni}$ & 0,18 & 0,40 \\
\hline & & $\mathrm{Cu}$ & $-0,24$ & $0,40 *$ \\
\hline & & $\mathrm{Zn}$ & $-0,40 *$ & $0,67 * *$ \\
\hline & & As & $-0,13$ & $0,65 * *$ \\
\hline & & $\mathrm{Cd}$ & $-0,46 *$ & $0,39 *$ \\
\hline & & $\mathrm{Ba}$ & $-0,21$ & 0,34 \\
\hline & & $\mathrm{Ce}$ & $-0,43 *$ & 0,18 \\
\hline & & Nd & $-0,58 * *$ & 0,30 \\
\hline & & Gd & $-0,69 * *$ & $0,44 *$ \\
\hline & & $\mathrm{Pb}$ & $-0,52 * *$ & 0,31 \\
\hline & & Mo & $-0,55 * *$ & 0,12 \\
\hline & & $\mathbf{F}^{-}$ & $-0,47 *$ & $0,37 *$ \\
\hline & & $\mathrm{Cl}^{-}$ & $-0,35$ & 0,35 \\
\hline & & $\mathrm{NO}_{3}^{-}$ & $-0,11$ & $0,57 * *$ \\
\hline & & $\mathrm{SO}_{4}{ }^{2-}$ & 0,16 & $0,53 * *$ \\
\hline & & $\mathrm{NH}_{4}^{+}$ & 0,06 & $0,57 * *$ \\
\hline & & $\mathbf{K}^{+}$ & $-0,39 *$ & 0,33 \\
\hline & & $\mathrm{Ca}^{++}$ & $-0,27$ & $0,36 *$ \\
\hline & acetic acid & $\mathrm{CH} 3 \mathrm{COOH}$ & 0,07 & 0,24 \\
\hline & glutaric acid & $\mathrm{HO} 2 \mathrm{C}(\mathrm{CH} 2) 3 \mathrm{CO} 2 \mathrm{H}$ & $-0,19$ & $-0,14$ \\
\hline & succinic acid & $\mathrm{HO} 2 \mathrm{C}(\mathrm{CH} 2) 2 \mathrm{CO} 2 \mathrm{H}$ & $-0,03$ & 0,16 \\
\hline & oxalic acid & $\mathrm{HO} 2 \mathrm{CCO} 2 \mathrm{H}$ & 0,14 & 0,31 \\
\hline & sum carboxylic acids & $\Sigma$ CAs & $-0,08$ & 0,25 \\
\hline & sum PAHs & $\Sigma 12 \mathrm{PAH}$ & $-0,25$ & $0,36 *$ \\
\hline & sum $n$-alkanes & $\Sigma \mathrm{C} 20-\mathrm{C} 32$ & $-0,46 *$ & 0,03 \\
\hline
\end{tabular}

Table 3 Spearman correlation $\left(r_{s} ; n>20\right)$ between meteo/PM chemical data and OP data (OPDT and OPDCFH; expressed per $\mathrm{m}^{3}$ ). 